УДК 535.016

\title{
ЭЛЛИПСОМЕТРИЧЕСКИЕ ХАРАКТЕРИСТИКИ ОПТИЧЕСКИХ КОНСТАНТ СЕРЕБРЯНЫХ ШЕРОХОВАТЫХ ПОВЕРХНОСТЕЙ
}

\author{
2018 () А. В. Цибульникова ${ }^{1 *}$, Е. И. Константинова ${ }^{1 *}$, А. Ю. Зюбин ${ }^{1 *}$, В. А. Слежкин ${ }^{2}$, \\ В. В. Брюханов ${ }^{1}$ И. Г. Самусев ${ }^{1}$, К. Ю. Максимова ${ }^{1}$ \\ ${ }^{1}$ Балтийский федеральный университет им. И. Канта \\ *Interdisciplinary Reference Centre: Functionalized Magnetic Materials for Energy and Biomedical Application \\ (FunMagMa), A. Невского, 14, 236016 Калининград, Россия \\ ${ }^{2}$ Калининградский государственный технический университет, Советский пр., 1 , \\ 236000 Калининград, Россия \\ e-mail: anna.tsibulnikova@mail.ru
}

Поступила в редакцию 22.02.2018

\begin{abstract}
Аннотация. Исследованы оптические и диэлектрические свойства шероховатых поверхностей пленок серебра, полученных электрохимическим методом. Определены коэффициенты отражения р- и s-поляризованного света на различных серебряных шероховатых поверхностях, проанализированы дисперсионные кривые функции диэлектрической проницаемости на модифицированных поверхностях серебра.
\end{abstract}

Ключевые слова: поверхностные плазмоны, шероховатые серебряные поверхности, коэффициенты отражения, пленки поливинилового спирта.

DOI: https://doi.org/10.17308/kcmf.2018.20/520

\section{ВВЕДЕНИЕ}

Высокая локализация электромагнитных полей на металлических наноструктурах различных форм и размеров, кластерах, наношероховатых поверхностях позволяет создавать уникальные гибридные фотовольтаические преобразователи, оптоэлектронные приборы, оптические сенсоры, спазеры и другие преобразователи, основанные на плазмонном резонансе $[1,2]$. Во всех приложениях наноплазмоники рассматриваются как делокализованные плазмоны, распространяющиеся по поверхности раздела металл-диэлектрик, так и локализованные поверхностные плазмоны (ПП), которые связаны с колебаниями электронной плотности металлических наноструктур, например, наночастиц (НЧ). Рассматриваются также процессы, связанные с усилением локальной электронной плотности на поверхности металлических нанотекстур в «горячих точках (“hot spots”)» [2], и эффекты, происходящие вблизи металлических нанотел, где возникает особое перераспределение электромагнитного поля (Enhancement to photon local density of states $(L D O S))[2,3,4]$.

Оптическая генерация плазмонов в среде сопровождается эффективной резонансной передачей энергии плазмонов в различных контактах с моле- кулярными структурами [5], усилением комбинационного рассеяния (КР) органических молекул и комплексов на металлической поверхности [6-8], изменением интенсивности излучения молекулярной люминесценции в результате индуктивно-резонансного диполь-дипольного переноса энергии с участием люминофоров [9-10] и др.

Практический интерес представляют исследования процессов генерации плазмонов на шероховатых металлических поверхностях с пленкой диэлектрика [11-13], на которых возникают плазмонные процессы переноса энергии на биологические молекулы и люминофоры [14-16].

В литературе приводится большое число новейших методов получения плазмонных устройств на основе НЧ и наноструктур, где во всех приложениях важны как поверхностные плазмоны (система «металл-диэлектрик»), так и локализованные плазмоны в НЧ. Отдельное место занимают наношероховатые поверхности благородных металлов, которые широко используются в системах генерации поверхностных плазмонов при создании, например, биосенсоров и терагерцовых излучателей электромагнитных волн.

Целью настоящей работы было изучение энергетических процессов преобразования оптическо- 
го излучения при генерации поверхностных плазмонов на серебряных шероховатых поверхностях, которые созданы электролитическими методами осаждения серебра в присутствии диэлектрика поливинилового спирта (ПВС).

\section{МЕТОДИКА ЭКСПЕРИМЕНТА}

Серебряные шероховатые пленки получали путем анодного растворения катодного покрытия в электролите серебрения. Электролит был следующего состава, г/л: калий железистосинеродистый 35 ; калий роданистый - 80; калий углекислый - 35; серебро (в пересчете на металл) - 25. Перед серебрением медную поверхность образца полировали пастой ГОИ до металлического блеска. После полировки поверхность промывали этанолом, затем обезжиривали в 5 \%-ном растворе карбоната натрия и активировали поверхность в 0.25 \%-ном растворе азотной кислоты в течение 10-15 с. Электроосаждение серебра проводили при температуре $18-20{ }^{\circ} \mathrm{C}$

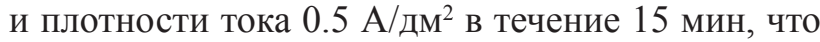
соответствовало матовой серебряной пленке. Затем изменяли шероховатость поверхности путем анодного растворения при плотности тока $5 \mathrm{~mA} / \mathrm{cm}^{2}$ серебряной пленки на слой толщиной 0.5 мкм в электролите серебрения. После электролиза серебряную поверхность промывали в течение 30 мин проточной водой от солей электролита и высушивали при комнатной температуре [17].

Таким образом, в настоящей работе исследовали электролитические пленки серебра с исходной шероховатостью поверхности - без анодного растворения (без АР), непосредственно после электроосаждения, а также пленки, подвергавшиеся анодному растворению (AP).

Коэффициенты отражения света и диэлектрические проницаемости образцов были измерены с помощью спектрального эллипсометра Auto SE (Horiba, Япония) в видимом диапазоне длин волн при стандартном угле падения $70^{\circ}$. Спектры отражения пленок ПВС на шероховатых поверхностях изучали на спектрофотометре Shimadzu UV-2600 (Япония) с фотометрической сферой.

Рельеф шероховатой поверхности серебряных пленок изучали на спектрально-лазерном комплексе Centaur-U с конфокальным микроскопом и с модулем сканирующего зондового микроскопа с оптической системой регистрации Certus Standart (Россия) в режиме полуконтактной атомно-силовой микроскопии (АСМ). Для работы использовали кантилеверы Mikro Masch с радиусом закругления зонда не более $\approx 10$ нм. Электронные изображения поверхности серебряных пленок получали с помощью электронного микроскопа (FIB-SEM) Zeiss Cross Beam-540. Экспериментальная ошибка всех оптических измерений составляла около $4 \%$.

\section{РЕЗУЛЬТАТЫ И ОБСУЖДЕНИЕ}

В первой серии экспериментов были измерены и проанализированы фотографии, полученные на электронном микроскопе, и сканы рельефа поверхности пленок Ag с различной шероховатостью, а именно: без АР (рис. $1 a, b)$ и с АР (рис. $1 c, d$ ), полученные методом сканирующей зондовой микроскопии и электронной микроскопии. Матовая поверхность серебряных пленок, изготовленных по технологии без АР состоит из плотно упакованных кристаллитов серебра (рис. $1 a$ ).

Из рис. $1 b-d$ видно, что шероховатость серебряных поверхностей при анодном растворении пленки Ag увеличивается (рис. $1 d$ ). Анализ сканов позволяет оценить значения шероховатости для поверхности без АР и с АР: $\xi_{1} \approx 0.11$ мкм и $\xi_{2} \approx 0.15$ мкм соответственно.

Далее были исследованы диэлектрические и оптические свойства серебряных пленок. На рис. $2 a$ представлены экспериментально полученные дисперсионные кривые функций действительной $\operatorname{Re}(\varepsilon)$ и мнимой $-\operatorname{Im}(\varepsilon)$ компонент диэлектрической проницаемости матовой серебряной поверхности (без АР).

Комплексная функция в части действительной $\operatorname{Re}(\varepsilon)$ и мнимой $\operatorname{Im}(\varepsilon)$ составляющих диэлектрическую проницаемость матовой серебряной поверхности численно совпадает со значениями для зеркальной поверхности серебра, представленными в литературе [18].

Полученные в работе электролитические поверхности серебра без АР (матовые) имеют представленное на рис. $2 a$ спектральное распределение функции $\varepsilon(\omega)$, которое может быть описано исключительно в рамках модели свободных колебаний электронов Друде при выполнении следующих условий: $\operatorname{Re}(\varepsilon)<0$ и $\operatorname{Im}(\varepsilon)>0$ согласно $[1,19-22]$. Для созданных серебряных пленок с анодным растворением наблюдается сложный вид спектральных зависимостей действительных частей диэлектрической проницаемости (рис. 2 ).

Из рис. $2 b$ видно, что действительная часть комплексной функции диэлектрической проницаемости имеет положительный знак в области до 520 нм, поэтому спектральное распределение функции $\varepsilon(\omega)$ для всех поверхностей не во всей видимой области подчиняется теории Друде-Зоммер- 


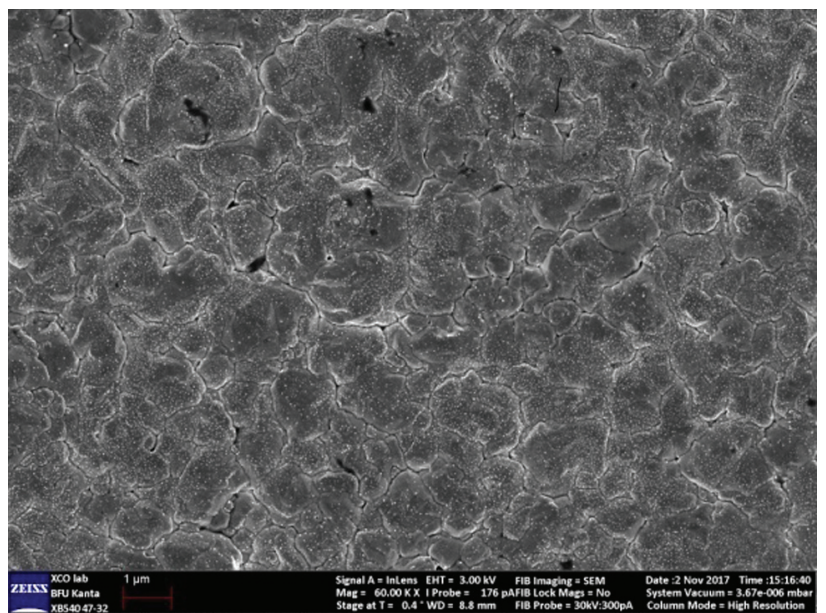

$a$

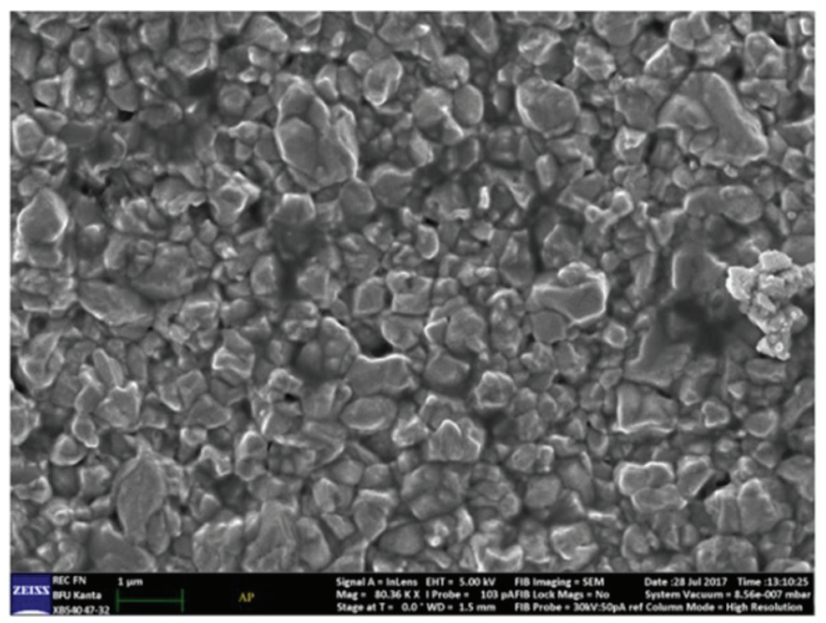

$c$

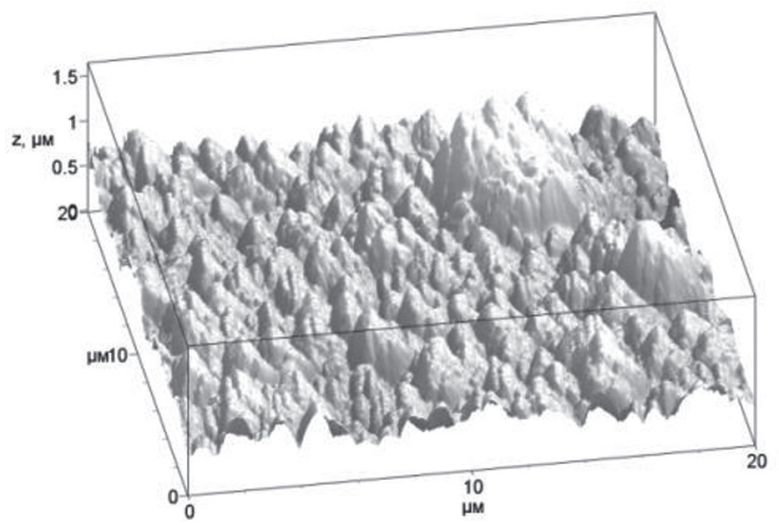

$b$

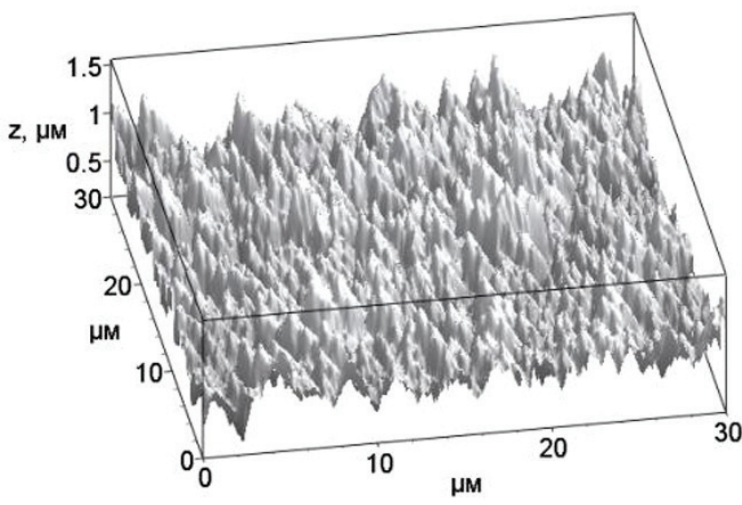

$d$

Рис. 1. Изображения, полученные на электронном микроскопе (FIB-SEM) Zeiss Cross Beam $540(a, c)$ и сканы $(b, d)$, полученные на сканирующем зондовом микроскопе комплекса Centaur-U поверхности без AP пленок $\mathrm{Ag}(a, b)$ и с $\mathrm{AP}(c, d)$. Толщина анодно-растворенного слоя $\mathrm{Ag}$ составляла $d=0.50$ мкм

[Fig. 1. Images obtained by electron microscope (FIB-SEM) Zeiss Cross Beam $540(a, c)$ and scans $(b, d)$ obtained by scanning probe microscope complex Centaur-U of films surface without $\operatorname{AD} \operatorname{Ag}(a, b)$ and with $\operatorname{AD}(c, d)$. The thickness of the anodically dissolved layer Ag was $d=0.50 \mu \mathrm{m}]$
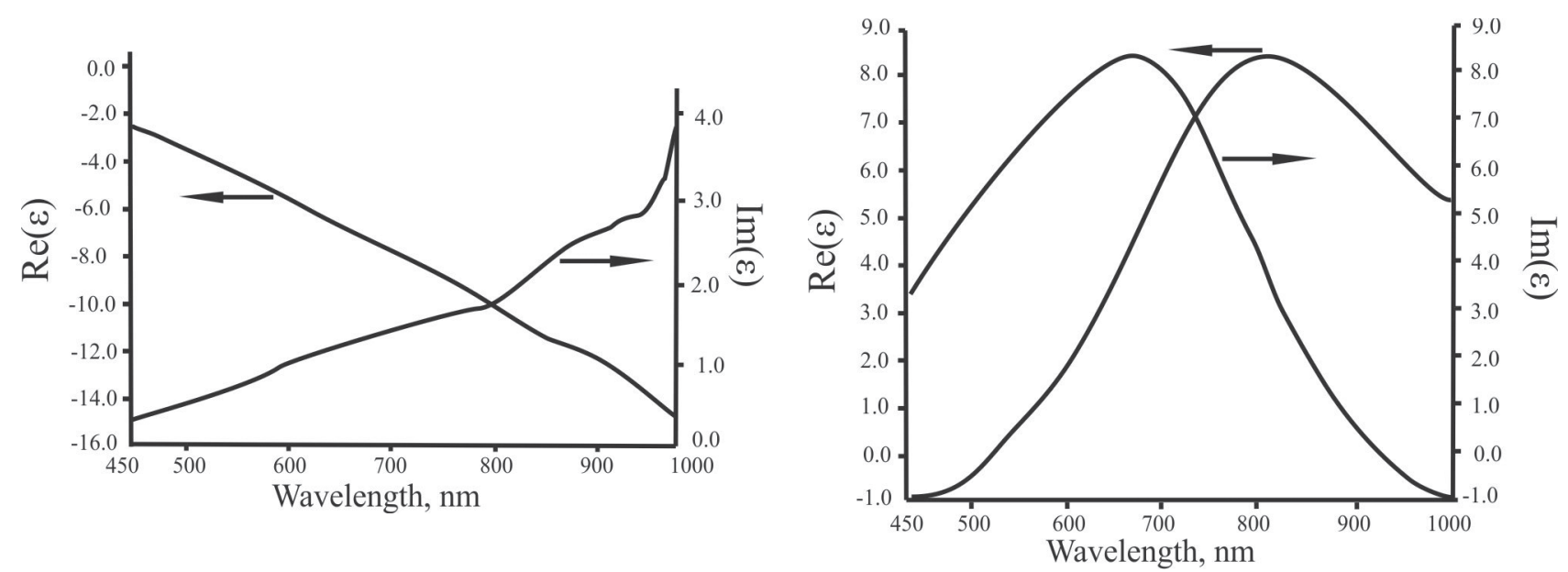

Рис. 2. Дисперсионные кривые действительной и мнимой компоненты диэлектрической проницаемости матовой $(a)$ и шероховатой $(b)$ поверхностей

[Fig. 2. Dispersion curves of the real and imaginary part dielectric permittivity of the matted $(a)$ and rough $(b)$ surfaces] 
фельда для свободных электронов. Обнаруженное спектральное распределение функций $\varepsilon(\omega)$, при котором резонансное значение действительной компоненты $\varepsilon(\omega)$ стремится к конечному значению, свойственно колебаниям поперечных симметричных Т-мод, согласно классификации в $[1,3,19,21]$. Приведенные экспериментальные значения функций $\operatorname{Re}(\varepsilon)>0$ и $\operatorname{Im}(\varepsilon)>0$ для шероховатых серебряных поверхностей согласуются с литературным обзором [1]. Как известно, отрицательная действительная часть функции диэлектрической проницаемости обусловливает существование на матовой поверхности только антисимметричных L-мод [23]. Можно предположить, что при исследовании оптических свойств электромагнитных $\mathrm{TM}_{1}$-мод серебряной шероховатой поверхности необходимо учитывать роль связанных электронов [11], действие которых подтверждается наличием положительной действительной компоненты функции $\varepsilon(\omega)$ в широком диапазоне частот. Полученные результаты спектрального распределения $\mathrm{TM}_{1}$-мод на шероховатых поверхностях, совпадают с теоретическими результатами фундаментальной работы [19]. Однако ранее в литературе не рассматривались экспериментальные зависимости модового состава электромагнитных колебаний от степени шероховатости серебряной поверхности.

Сложные дисперсионные кривые функций действительной и мнимой диэлектрической проницаемости с экстремумом (рис. $2 b$ ) свидетельствуют о наличии хаотической шероховатости серебряных пленок с АР-технологией получения шероховатости.
На рис. 3 представлены спектры отраженного поляризованного излучения с р- $(a)$ и s-поляризацией $(b)$ пленок с АР шероховатостью. Наблюдается минимум функции отражения с р- поляризацией в области 700 нм, характерный для поверхностей с «грубой» шероховатостью [11]. Коэффициент отражения такой поверхности на длине волны $\lambda=450$ нм составляет $R \approx 0.67$.

Поскольку известно существование плазмонного резонанса для наночастиц серебра в области 420 нм [1], то представляло интерес рассмотреть изменение оптических характеристик, в частности, $R_{\mathrm{p}}$ и $R_{\mathrm{s}}$ серебряных шероховатых поверхностей на данной длине волны и в ближайшей к ней области существования поверхностных плазмонов на $\lambda=455$ нм. Данные приведены в табл. 1 .

Анализ данных позволил заключить следующее.

Во-первых, величины коэффициентов отражения $R_{\mathrm{p}}$ и $R_{\mathrm{s}}$ поляризованного света, отраженного от поверхности пленок $\mathrm{Ag}$, уменьшаются с увеличением шероховатости при переходе от пленок без АР к пленкам с $\mathrm{AP}\left(R_{\mathrm{p}}<R_{\mathrm{s}}\right)$, примерно, в 4 раза. При этом коэффициенты отражения поляризованного света $R_{\mathrm{p}}$ и $R_{\mathrm{s}}$ для пленок без АР приблизительно одинаковы при длине волны отражения $\lambda=455$ нм, что связано с увеличением отражательной способности пленок с поверхностью без АР - это констатировалось выше. Можно предположить, что на хаотически расположенных элементах шероховатых поверхностей серебряных пленок происходит изменение интенсивности отраженного s- и р-поляризованного света с одновременной генерацией ПП и более интенсив-

Таблица 1. Коэффициенты отражения поверхности образцов на длинах волн $\lambda=420$ нм и 455 нм, измеренные на эллипсометре Horiba (Япония) при стандартном угле падения $\alpha=70^{\circ}$

[Table 1. Reflection coefficients of the sample surfaces at wavelengths $\lambda=420 \mathrm{~nm}$ and $455 \mathrm{~nm}$, measured by ellipsometer (Horiba, Japan) at the standard angle of incidence $\alpha=70^{\circ}$ ]

\begin{tabular}{|c|c|c|c|c|c|c|}
\hline \multirow{2}{*}{$\begin{array}{c}\text { Поверхность } \\
\text { [Surface] }\end{array}$} & \multicolumn{3}{|c|}{$\lambda=420$ нм } & \multicolumn{3}{|c|}{$\lambda=455$ нм } \\
\cline { 2 - 7 } & $R_{\mathrm{p}}{ }^{*}$ & $R_{\mathrm{s}}^{*}$ & $R_{\mathrm{e}}{ }^{* *}$ & $R_{\mathrm{p}}^{*}$ & $R_{\mathrm{s}}^{*}$ & $R_{\mathrm{e}}^{* *}$ \\
\hline $\begin{array}{c}\text { Ag без AP } \\
{[\mathrm{Ag} \text { without AD] }}\end{array}$ & 0.50 & 0.84 & 0.67 & 0.85 & 0.84 & 0.67 \\
\hline $\begin{array}{c}\text { Ag c AP } \\
{[\mathrm{Ag} \text { with AD] }}\end{array}$ & 0.15 & 0.68 & 0.41 & 0.16 & 0.67 & 0.50 \\
\hline $\begin{array}{c}\text { ПВC, } d=5.0 \text { мкм на } \\
\text { поверхности Ag c AP } \\
\begin{array}{c}\text { [PVA, } d=5.0 \mu \mathrm{m} \text { on Ag } \\
\text { surface with AD] }\end{array}\end{array}$ & 0.04 & 0.28 & 0.19 & 0.044 & 0.28 & 0.19 \\
\hline
\end{tabular}

$* R_{\mathrm{p}}, R_{\mathrm{s}}-$ коэффициенты отражения р-и s-поляризованного света;

$\left[* R_{\mathrm{p}}, R_{\mathrm{s}}\right.$ - reflection coefficients $\mathrm{p}$-и s-polarized light];

$* * R_{\mathrm{e}}-$ коэффициенты отражения неполяризованного света при измерении на эллипсометре $(e)$.

$\left[* * R_{\mathrm{e}}-\right.$ reflection coefficients nonpolarized light measured by ellipsometer $\left.(e)\right]$. 
А. В. ЦИБУЛЬНИКОВА, Е. И. КОНСТАНТИНОВА, А. Ю. ЗЮБИН, В. А. СЛЕЖКИН, В. В. БРЮХАНОВ, И. Г. САМУСЕВ

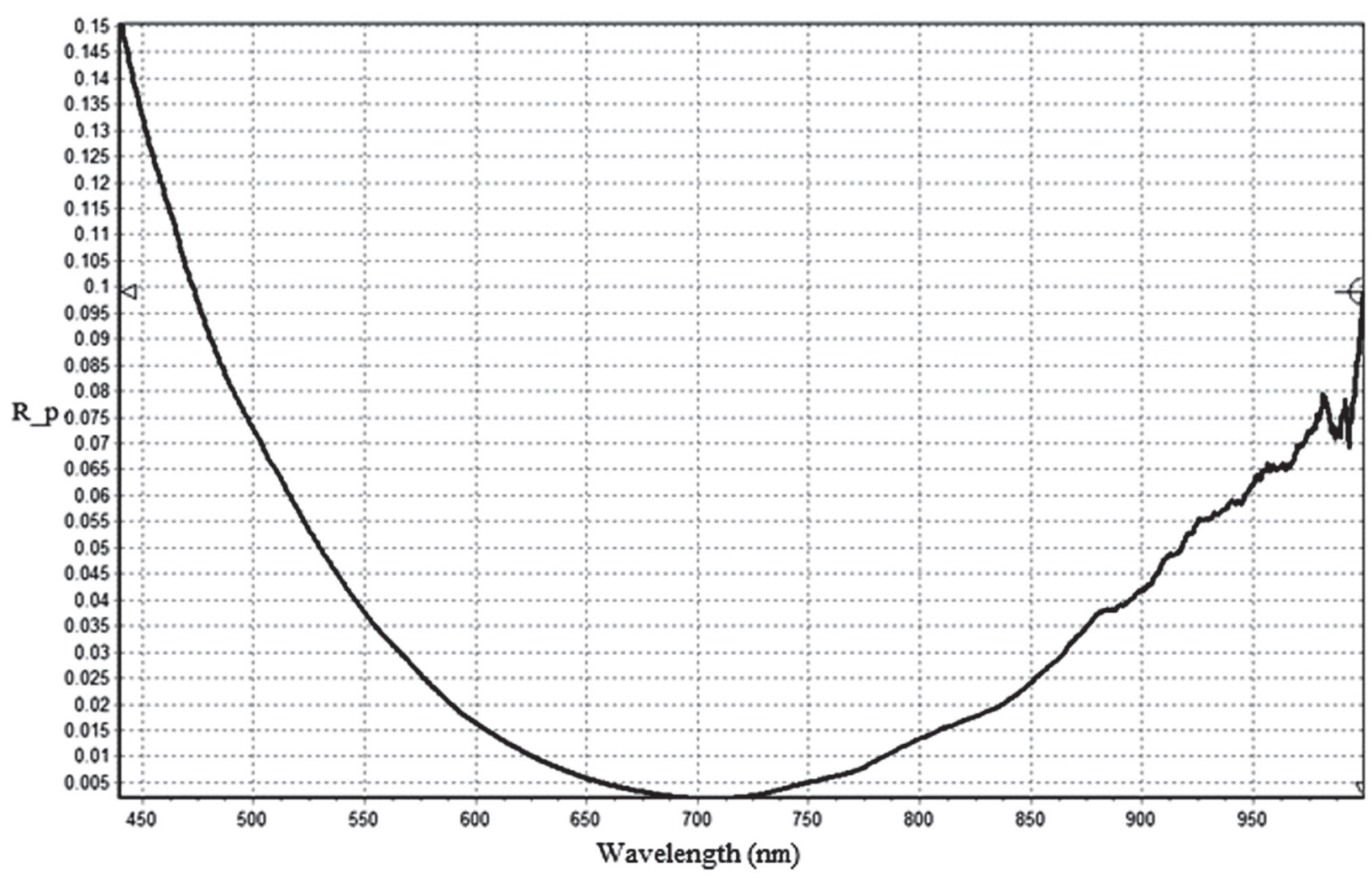

$a$

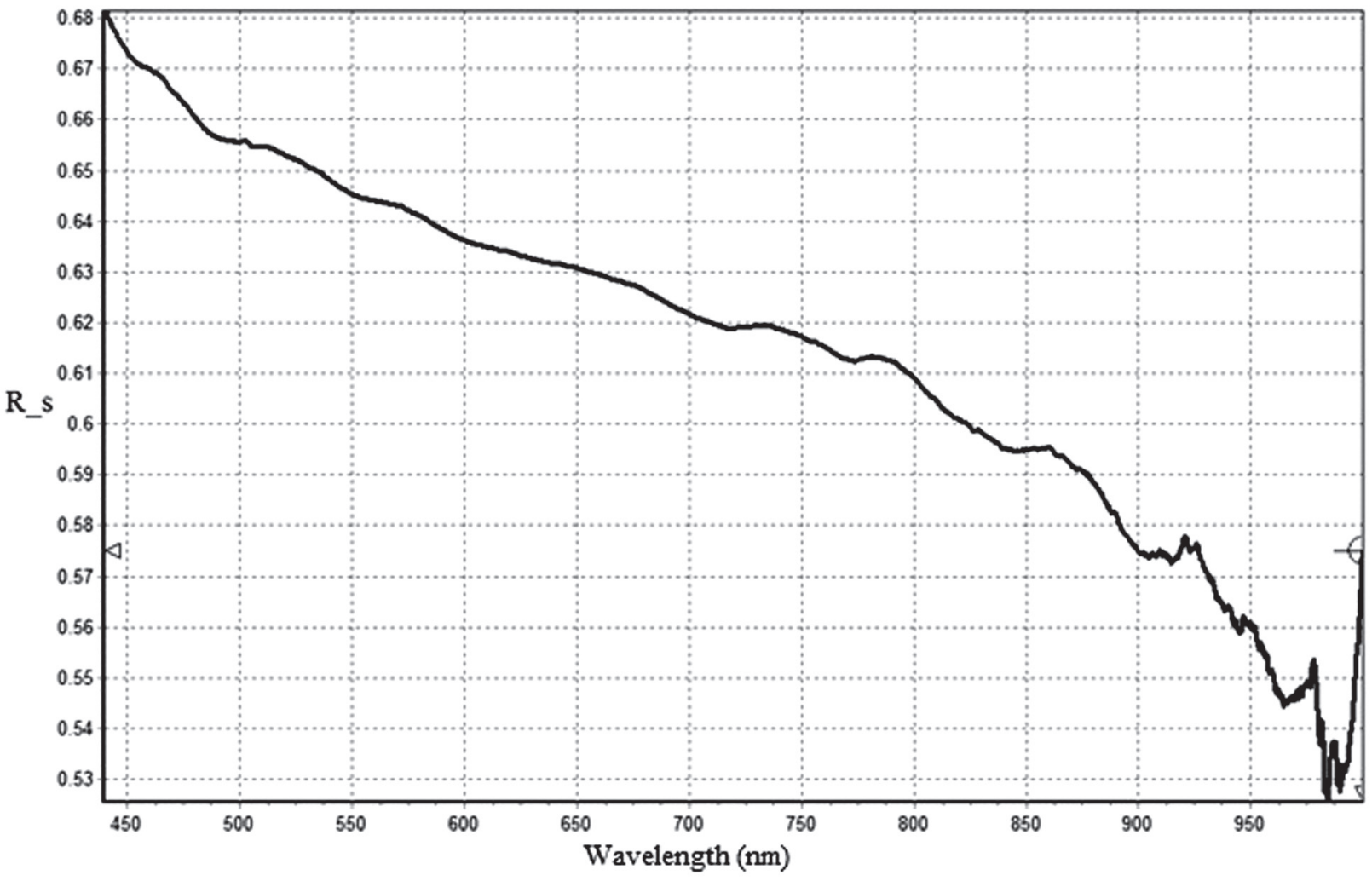

$b$

Рис. 3. Спектры отраженного поляризованного света р- $(a)$ и s-поляризации $(b)$ шероховатых АР-пленок [Fig. 3. Spectra of reflected p- $(a)$ and s-polarization $(b)$ polarized light of rough AD films] 
ным поглощением р-поляризованного света для микро- и наношероховатых поверхностей $[18,21]$.

Далее представляло интерес количественно оценить влияние шероховатости серебряных пленок на интенсивность отраженного р- и s-поляризованного света и эффективность генерации ПП в результате созданной технологии без АР и с АР шероховатых поверхностей Ag. С этой целью была оценена доля $\eta$ энергии падающего р-поляризованного света, превращенной в энергию ПП шероховатых поверхностей, используя данные работ [19-21]:

$$
\eta=\frac{\Delta R_{\mathrm{p}}^{\mathrm{ps}}}{R_{\mathrm{p}}}=\xi^{2} a^{2} f(\omega, \varepsilon, \theta, k),(1)
$$

где $\xi$ - шероховатость поверхности; $a$ - среднее стандартное расстояние между неровностями (длина корреляции или расстояние между бугорками); $f(\omega, \varepsilon, \theta, k)$ - функция, зависящая от оптических микроскопических параметров поверхности [11, 20]. Величина $\frac{\Delta R_{\mathrm{p}}^{\mathrm{ps}}}{R_{\mathrm{p}}}$ показывает долю падающего p-поляризованного излучения, превращенного в поверхностные плазмоны.

Соотношение $\eta_{1} / \eta_{2}$, характеризующее влияние степени шероховатости поверхности Ag (без AP и с АР) на преобразование энергии падающего pполяризованного света в энергию ПП, определяли, считая, что функция $f(\omega, \varepsilon, \theta, k)$ меняется незначительно с изменением шероховатости поверхности, поэтому, из (1) следует:

$$
\eta_{1} / \eta_{2}=\left(\xi_{1} a_{1}\right)^{2} /\left(\xi_{2} a_{2}\right)^{2} \text {. }
$$

Здесь индексы 1 и 2 соответствуют случаям без АР и с АР соответственно.

В формулу (2) подставляли $\xi_{1} \approx 0.11$ мкм и $\xi_{2} \approx 0.15$ мкм, которые получали путем обработки АСМ-микроскопических сканов поверхности, полученных на сканирующем зондовом микроскопе, а также полагали, что длина корреляции $а$ одинакова для обеих поверхностей.

Расчет показал, что $\eta_{1} / \eta_{2}$ равно 1.86 , поэтому можно утверждать, что на более шероховатой поверхности (AР) преобразование энергии р-поляризованного света в энергию ПП является более эффективным. Полученные значения шероховатости исследованных серебряных пленок с технологиями без АР и с АР можно отнести к поверхностям с грубой шероховатостью, на которых генерируются плазмоны под влиянием падающего оптического излучения.

После нанесения пленки диэлектрика (ПВС) на шероховатую поверхность Ag (без АР или с АР) из- меняется спектральный состав отраженного света. Коэффициенты отражения света от шероховатых пленок серебра без АР и с АР отличаются примерно в два раза, что обусловлено различной степенью шероховатости, причем длина волны поглощения шероховатых серебряных пленок остается постоянной.

При этом в работе было обнаружено, что максимум спектра поглощения шероховатых пленок серебра с пленками ПВС не смещается и остается постоянным, хотя в работе были исследованы пленки диэлектрика (ПВС) толщиной от 1.0 до 10.0 мкм. Следовательно, физические процессы поглощения и рассеяния поверхностных плазмонов в системе металл-диэлектрик остаются одинаковыми независимо от толщины диэлектрика. Заметим также, что коэффициенты отражения серебряной поверхности с пленкой ПВС на длинах волн 420 и 450 нм практически одинаковы.

Следует отметить, что глубина проникновения поля ПП в диэлектрик по данным разных исследований, например $[1,24,25]$, значительно разнится и зависит от длины волны возбуждения ПП в видимой области, а также от рода металла и технологии получения шероховатости его поверхности. Глубина проникновения ПП в диэлектрик из металла не поддается точной количественной оценке, поэтому для шероховато-пористых поверхностей металлов обычно используют различные методы моделирования [26]. В связи с этим полученные нами экспериментальные данные являются оценочными, причем сделаны впервые для шероховатых серебряных поверхностей.

При создании биосенсоров на основе серебряных поверхностей, в том числе и НЧ, огромное значение имеют спектрально-кинетические особенности фотопроцессов с участием плазмонов.

\section{ЗАКЛЮЧЕНИЕ}

Таким образом, в настоящей работе экспериментально исследованы оптические процессы преобразования поверхностных плазмонов при падении электромагнитного излучения на шероховатые серебряные поверхности с пленкой ПВС. Изучены оптические и диэлектрические свойства шероховатых поверхностей электроосажденых пленок серебра, определена эффективность преобразования энергии р-поляризованного света в энергию ПП в зависимости от шероховатости Ag.

Показано, что с помощью технологии, разработанной на основе электрохимических методов, можно изготавливать серебряные шероховатые поверхности с осажденными пленками полимеров, 
в частности ПВС, которые могут найти различное применение в опто-люминесцентных датчиках с заданными оптическими свойствами.

\section{СПИСОК ЛИТЕРАТУРЫ}

1. Климов В. В. Наноплазмоника. М.: Физматлит, 2009,480 c.

2. Gaponenko S. V. Introduction to Nanophotonics. Cambridge: Cambridge University Press, 2010, 716 p.

3. Sarid D., Challener W. Modern Introduction to Surface Plasmons: Theory, Mathematical Modeling and Applications. New York: Cambridge University Press, 2010, 371 p.

4. Maier A. Plasmonic Fundamentals and Application. UK: Springer, 2007, $221 \mathrm{p}$.

5. Govorov A. O., Lee J., Kotov N. A. // Phys. Rev., 2007, vol. 76, p. 125308. DOI: 10.1103/PhysRevB.76.125308

6. Buja O. M., Mircescu N. E., Leopold N. // J. Appl. Spectroscopy, 2014. vol. 81, № 3, pp. 411-415. DOI: 10.1007/s10812-014-9946-1

7. Емельянов В. И., Коротеев И. И. // УФН, 1981, т. 135, № 2, c. 345-361. DOI: 10.1070/PU1981v024n10ABEH 004812

8. Strelchuk V. V, Kolomys O. F., Golichenko B. O., Boyko M. I., Kaganovich E. B., Krishchenko I. M., Kravchenko S. O., Lytvyn O. S., Manoilov E. G., Nasieka Iu. M. // Semiconductor Physics Quantum Electronics \& Optoelectronics, 2015, vol. 18, № 1, pp. 46-52. DOI: 10.15407/ spqeo18.01.046

9. Чмерева Т. М., Кучеренко М. Г. // Известия высших учебных заведений. Физика, 2014, т. 57, № 10, c. $116-121$.

10. Venkatapathi M., Tiwari A. K. // J. Appl. Phys., 2012, vol. 112, pp. 32-47. DOI: org/10.1063/1.4736544

11. Drachev V. P., Chettiar U. K., Kildishev A. V., HsiaoKuan Y., Shalaev V. M. // Opt. Express, 2008, vol. 16, № 2, pp. 1186-1195. DOI: 10.1364/OE.16.001186

12. Коганович Э. Б., Кравченко С. А., Максименко Л. С., Манойлов Э. Г., Матяш И. Е., Мищук О. Н, Руденко С. П., Сердега Б. К. // Оптика и спектроскопия,
2011, vol. 110, № 4, c. 552-560. DOI: https://doi. org/10.1134/S0030400X11040126

13. Руденко С. П., Стеценко М. А., Крищенко И. М., Максименко Л. С., Каганович Э. Б., Сердега Б. К. // Оптика и спектроскопия, 2016, т. 120, № 4, с. 569-575. DOI: $10.7868 / \mathrm{S} 0030403416040206$

14. Kanwarjeet K. Optical Biosensing Using Localized Surface Plasmon Resonance of Gold Nanoparticles. Waterloo, Ontario, Canada, 2011, 219 p.

15. Сотников Д. В., Жердев А. В., Дзантиев Б. Б. // Успехи биологической химии, 2015, т. 55, с. 391-420.

16. Zhao Z., Carpenter M. A. // J. Phys. Chem. C., 2013, vol. 117, № 21, pp. 11124-11132. DOI: 10.1021/jp400837r

17. Слежкин В. А., Горлов Р. В. // Известия КГТУ, 2011, № 20, c. 115-122.

18. Weber M. J. Handbook of Optical Materials, CRC: New York, 2003, 499 p.

19. Ford G. W., Weber W. H. // Phys. Reports, 1984, vol. 113, № 4, pp. 195-287. DOI: http://dx.doi. org/10.1016/0370-1573(84)90098-X.

20. Бродский А. М., Урбах М. И. // УФН, 1982, т. 138, вып. 3, с. 413-453. DOI: 10.3367/UFNr.0138.198211b. 0413

21. Агранович В. М., Милс Д. Л. Поверхностные поляритоны. Электромагнитные волны на поверхностях и гранищы раздела сред. М.: Наука, 1985, 525 с.

22. Johnson P. B., Christy R. W. // Phys. Rev., 1972, vol. 6, № 12, pp. 4370-4379. DOI: https://doi.org/10.1103/ PhysRevB.6.4370

23. Новохотный Л., Хехт Б. Основы нанооптики. М.: Физматлит, 2009, 484 c.

24. Kennedy B. J., Spaeth S., Dickey M., Carron K. T. // J. Physical Chemistry B, 1999, vol. 103, pp. 3640-3646. DOI: $10.1021 / \mathrm{jp} 984454 \mathrm{i}$

25. Гигантское комбинаџионное рассеяние: [Сб. статей под редакцией Р. Ченга, Т. Фуртака]. М.: Мир, 1984, гл. 11, 407 с.

26. Svitasheva S. Modelling Methods of Optical Inhomogeneous Structures. Application of Ellipsometry. Saarbruecken: Lambert Academic Publishing, 2013, 112 p.

\title{
ELLIPSOMETRIC CHARACTERISTICS OF THE OPTICAL CONSTANTS OF ROUGH SILVER SURFACES
}

2018 (c) A. V. Tcibulnikova ${ }^{1 *}$, E. I. Konstantinova ${ }^{1 *}$, A. Y. Zybin ${ }^{1 *}$, V. A. Slezhkin ${ }^{2}$, V. V. Bryukhanov ${ }^{1}$ I. G. Samusev ${ }^{1}$, K. Yu. Maksimova ${ }^{1}$

${ }^{1}$ Immanuel Kant Baltic Federal University,

"Interdisciplinary Reference Centre: Functionalized Magnetic Materials for Energy and Biomedical Application (FunMagMa), 14 A. Nevskogo str., 236016 Kaliningrad, Russia

${ }^{2}$ Kaliningrad State Technical University, 1 Sovetsky ave., 236000 Kaliningrad, Russia e-mail: anna.tsibulnikova@mail.ru

Received 22.02.2018

\begin{abstract}
The highly localized electromagnetic fields in metal nanostructures of various shapes and
\end{abstract} sizes allows creating unique hybrid photovoltaic converters, optoelectronic devices, optical sensors, 
and other converters based on plasmon resonance. This paper shows that the technology developed based on electrochemical methods makes it possible to produce rough silver surfaces with deposited polymer films in which surface plasmons with a special spectral distribution can be generated. It describes the processes of transforming electromagnetic radiation incident on rough silver surfaces obtained by the electrochemical method with anodic dissolution (AD) and without AD. This work presents the reflection coefficients s- and p-polarized light which were measured on surface with AD and without AD. The reflection coefficients of polarized light were compared with coefficients of nonpolarised light on different rough silver surfaces. It is also shown that with an increase in surface roughness by $0.15 \mu \mathrm{m}$ the reflection coefficients decrease by 4 times.

It was established that the conversion of the energy of the p-polarized light into the energy of surface plasmons on the anodically dissolved surface is more effective than on the surface without anodic dissolution. The efficiency of the conversion of incident radiation into the energy of surface plasmons with the due account of the roughness value was calculated. The dispersion curves of the real and imaginary part of dielectric permittivity function were analysed. It was shown that dispersion curves have a complex appearance, which is associated with the roughness of the anodically dissolved surface of silver. The results obtained can be used to develop opto- and biosensors and in photovoltaics for creation of solar energy converters.

Keywords: surface plasmons, rough silver surfaces, reflection coefficients, polyvinyl alcohol films.

DOI: https://doi.org/10.17308/kcmf.2018.20/520

\section{REFERENCES}

1. Klimov V. V. Nanoplazmonika [Nanoplasmonics]. Moscow, Fizmatlit Publ., 2009, 480 p. (in Russ.)

2. Gaponenko S. V. Introduction to Nanophotonics. Cambridge: Cambridge University Press, 2010, 716 p.

3. Sarid D., Challener W. Modern Introduction to Surface Plasmons: Theory, Mathematical Modeling and Applications. New York: Cambridge University Press, 2010, $371 \mathrm{p}$.

4. Maier A. Plasmonic Fundamentals and Application. UK: Springer, 2007, 221 p.

5. Govorov A. O., Lee J., Kotov N. A. Phys. Rev., 2007. vol. 76, p. 125308. DOI: 10.1103/PhysRevB.76.125308

6. Buja O. M., Mircescu N. E., Leopold N. J. Appl. Spectroscopy, 2014, vol. 81, no. 3, pp. 411-415. DOI: 10.1007/s10812-014-9946-1

7. Emel'yanov V. I., Koroteev I. I. Physics-Uspekhi [Advances in Physical Sciences)], 1981, vol. 135, no. 2, pp. 345-361. DOI: 10.1070/PU1981v024n10ABEH004812

8. Strelchuk V. V, Kolomys O. F., Golichenko B. O., Boyko M. I., Kaganovich E. B., Krishchenko I. M., Kravchenko S. O., Lytvyn O. S., Manoilov E. G., Nasieka Iu. M. Semiconductor Physics Quantum Electronics \& Optoelectronics, 2015, vol. 18, no. 1, pp. 46-52. DOI: 10.15407/ spqeo18.01.046

9. Chmereva T. M., Kucherenko M. G. Izvestiya vysshikh uchebnykh zavedenii. Fizika [Russian Physics Journal], 2014, vol. 57, no. 10, pp. 116-121.

10. Venkatapathi M., Tiwari A. K. J. Appl. Phys., 2012, vol. 112, pp. 32-47. DOI: org/10.1063/1.4736544

11. Drachev V. P., Chettiar U. K., Kildishev A.V., HsiaoKuan Y., Shalaev V. M. Opt. Express, 2008, vol. 16, no. 2, pp. 1186-1195. DOI: 10.1364/OE.16.001186
12.KoganovichE.B., Kravchenko S.A., Maksimenko L. S., Manoilov E. G., Matyash I. E., Mishchuk O. N, Rudenko S. P., Serdega B. K. Optika i spektroskopiya [Optics and Spectroscopy], 2011, vol. 110, no. 4, pp. 513-521. DOI: https://doi.org/10.1134/S0030400X11040126

13. Rudenko S. P., Stetsenko M. A., Krishchenko I. M., Maksimenko L. S., Kaganovich E. B., Serdega B. K. Optika i spektroskopiya [Optics and Spectroscopy], 2016, vol. 120, no. 4, pp. 569-575. DOI: 10.7868/S0030403416040206

14. Kanwarjeet K. Optical Biosensing Using Localized Surface Plasmon Resonance of Gold Nanoparticles. Waterloo, Ontario, Canada, 2011, 219 p.

15. Sotnikov D. V., Zherdev A. V.,Dzantiev B. B. Uspekhi Biologicheskoi Khimii [Biological Chemistry Reviews], 2015, vol. 55, pp. 391-420. Available at: http:/www.fbras.ru/wpcontent/uploads/2017/10/Sotnikov.pdf (in Russ.)

16. Zhao Z., Carpenter M. A. J. Phys. Chem. C., 2013, vol. 117, no. 21, pp. 11124-11132. DOI: 10.1021/ jp400837r

17. Slezhkin V. A., Gorlov R. V. Izvestiya KGTU, 2011, no. 20, pp. 115-122. (in Russ.)

18. Weber M. J. Handbook of Optical Materials, CRC: New York, 2003, 499 p.

19. Ford G. W., Weber W. H. Phys. Reports, 1984, vol. 113, no. 4, pp. 195-287. DOI: http://dx.doi.org/10.1016/03701573(84)90098-X

20. Brodskii A. M., Urbakh M. I. Physics-Uspekhi [Advances in Physical Sciences)], 1982, vol. 138, iss. 3, pp. 413-453. DOI: 10.3367/UFNr.0138.198211b.0413

21. Agranovich V. M., Mils D. L. Poverkhnostnye polyaritony. Elektromagnitnye volny na poverkhnostyakh $i$ granitsy razdela sred [Surface Polaritons. Electromagnetic Waves on Surfaces and Media Interfaces]. Moscow, Nauka Publ., 1985, 525 p. (in Russ.) 
22. Johnson P. B., Christy R. W. Phys. Rev., 1972, vol. 6, no. 12, pp. 4370-4379. DOI: https://doi.org/10.1103/ PhysRevB.6.4370

23. Novokhotnyi L., Khekht B. Osnovy nanooptiki [Fundamentals of Nanooptics]. Moscow, Fizmatlit Publ., 2009, 484 p. (in Russ.)

24. Kennedy B. J., Spaeth S., Dickey M., Carron K. T. J. Physical Chemistry B, 1999, vol. 103, pp. 3640-3646. DOI: $10.1021 /$ jp984454i
25. Surface Enhanced Raman Scattering. Edited by Richard K. Chang Yale University New Haven, Connecticut and Thomas E. Furtak Rensselaer Polytechnic Institute Troy, New York Plenum Press ; New York and London, 1982, pp. 203-221.

26. Svitasheva S. Modelling Methods of Optical Inhomogeneous Structures. Application of ellipsometry. Saarbruecken: Lambert Academic Publishing, 2013, $112 \mathrm{p}$.
Цибульникова Анна Владимировна - к. ф.-м. н., н. с., БФУ им. И. Канта; тел.: +7(900) 5611976, e-mail: anna.tsibulnikova@mail.ru

Константинова Елизавета Ивановна - аспирант, м. н. с., БФУ им. И. Канта; тел.: +7(952) 0563748, e-mail: konstantinovaeliz@gmail.com

Зюбин Андрей Юрьевич - м. н. с., БФУ им. И. Канта; тел.: +7(906) 2127492, e-mail: azubin@mail. $\mathrm{ru}$

Слежкин Василий Анатольевич - к. х. н., доцент, КГТУ; тел.: +7(911) 4583658, e-mail: vslezhkin@mail.ru

Брюханов Валерий Вениаминович - д. ф.-м. н., профессор, с. н. с., БФУ им. И. Канта; тел.: +7(906) 2305209, e-mail: vslezhkin@mail.ru

Самусев Илья Геннадьевич - к. ф.-м. н., зам. директора института по научной работе ФМнИТ БФУ им. И. Канта; тел.: +7(911) 8620458, e-mail: the_samusev@yahoo.com

Максимова Ксения Юрьевна - н.с., БФУ им. И. Канта; тел.: +7(981) 4622544, e-mail: KMaksimova@kantiana.ru
Anna V. Tcibulnikova - Cand. Sci. (Phys. -Math.), Researcher, Immanuel Kant Baltic Federal University; tel.: +7(900) 5611976, e-mail: anna.tsibulnikova@ mail.ru

Elizaveta I. Konstantinova - postgraduate student, Junior Researcher, Immanuel Kant Baltic Federal University; tel.: +7(952) 0563748, e-mail: konstantinovaeliz@gmail.com

Andrey Y. Zybin -Junior Researcher, Immanuel Kant Baltic Federal University; tel.: +7(906) 2127492, e-mail: azubin@mail.ru

Vasily A. Slezhkin-Cand. Sci. (Chem.), Associate Professor, Kaliningrad Technical State University; tel.: +7(911) 4583658, e-mail: vslezhkin@mail.ru

Valery V. Bryukhanov - Dr. Sci. (Phys.-Math.), Professor, Senior Researcher, Immanuel Kant Baltic Federal University; tel.: +7(906) 2305209, e-mail: vslezhkin@mail.ru

Ilya G. Samusev-Cand. Sci. (Phys. -Math.), ViceHead of the Institute of Physics, Math. and IT for Research, Immanuel Kant Baltic Federal University; tel.: +7(911) 8620458, e-mail: the_samusev@yahoo. com

Kseniya Yu.Maksimova - Researcher, Immanuel Kant Baltic Federal University; tel.: +7 (981) 4622544, e-mail:KMaksimova@kantiana.ru 